\title{
Role of Human Leukocyte Antigens (HLA) in Autoimmune Diseases
}

\author{
Gergely Bodis · Victoria Toth $\cdot$ Andreas Schwarting
}

Received: January 3, 2018 / Published online: March 7, 2018

(C) The Author(s) 2018. This article is an open access publication

\section{ABSTRACT}

Since the discovery of HLA 60 years ago, it has contributed to the understanding of the immune system as well as of the pathogenesis of several diseases. Aside from its essential role in determining donor-recipient immune compatibility in organ transplantation, HLA genotyping is meanwhile performed routinely as part of the diagnostic work-up of certain autoimmune diseases. Considering the ability of HLA to influence thymic selection as well as peripheral anergy of $\mathrm{T}$ cells, its role in the pathogenesis of autoimmunity is understandable. The aim of this paper is to provide a brief overview of the role and current clinical relevance of HLA-B27 in spondyloarthritis and HLA-B51 in Behçet's disease as well as HLA-DQ2/DQ8 in celiac

Enhanced content To view enhanced content for this article go to https://doi.org/10.6084/m9.figshare.59011 63.

G. Bodis · V. Toth · A. Schwarting $(\bowtie)$

Division of Rheumatology and Clinical

Immunology, University Hospital, Mainz, Germany

e-mail: schwarting@uni-mainz.de

A. Schwarting

ACURA Center for Rheumatic Diseases, Bad

Kreuznach, Germany

G. Bodis · V. Toth

Institut für Medizinische Diagnostik $\mathrm{GmbH}$, Bioscientia Labor Ingelheim, Ingelheim Am Rhein, Germany disease and HLA-DRB1 in rheumatoid arthritis and to discuss possible future implications.

Keywords: Autoimmunity; Behçet's disease; Celiac disease; Genotyping; Human leucocyte antigen; MHC class I; MHC class II; Shared epitopes; Spondylarthritis; Rheumatoid arthritis

\section{INTRODUCTION}

The human leukocyte antigen (HLA) system, which corresponds to the major histocompatibility complex (MHC) in humans, plays a pivotal role in the antigen presentation of intracellular and extracellular peptides and the regulation of innate and adaptive immune responses. The aim of this paper is to provide a brief overview of the role and current clinical relevance of HLA-B27 in spondyloarthritis and HLA-B51 in Behçet's disease as well as HLADQ2/DQ8 in celiac disease and HLA-DRB1 in rheumatoid arthritis and to discuss possible future implications. This article is based on previously conducted studies and does not contain any studies with human participants or animals performed by any of the authors. 


\section{MHC CLASS I: HLA-B27 AND SPONDYLOARTHRITIS (SPA)}

The clinical entities of the spondyloarthritis (SpA) group are inflammatory diseases with distinctive axial and/or peripheral joint involvement, enthesitis, and frequently accompanied by inflammatory eye disease, especially anterior uveitis. SpA belongs to the most common rheumatic diseases with a prevalence of $0.4-1.3 \%$ in the US with similar prevalence in Europe and lower rates in African and Asian populations $[1,2]$. It also poses a major burden both socially and economically due to work disability occurring in $18.5-21 \%$ of SpA patients $[3,4]$.

One of the common denominators among distinct entities of the SpA family is the frequent association with MHC class I molecules, particularly with HLA-B27, which has obtained significance in the routine diagnostic work-up in the last decades. HLA-B27 belongs to the MHC class I molecules. Its main function is the presentation of intracellular peptides to CD8positive $\mathrm{T}$ lymphocytes. These MHC class I-restricted $\mathrm{T}$ cells possess cytotoxic or regulatory function, their activation leading accordingly either to tolerance, when the presented peptides are recognized as "self", to activation of cellmediated immunity in case "non-self" antigens are presented or to a maladaptive autoimmune response if the "self" antigen is misrecognized.

\section{Epidemiology}

The prevalence of HLA-B27 shows a pronounced north-south gradient in the normal population: it is lowest in the equatorial region $(\sim 0 \%)$ and highest in northern countries (30-40\%). This geographical difference may be attributable to HLA-B27 carriers being more susceptible to malaria and also showing a more severe disease course. This susceptibility might have led to the negative selection of HLA-B27-positive individuals in areas endemic for malaria [5]. The population of Papua New Guinea and Eskimos seem to have the highest prevalence of HLA-B27, with $13-53 \%[6,7]$ and $25-50 \%[8,9,10]$, respectively. Among Caucasians, the prevalence is $6-10 \%$. The prevalence is lower in Chinese $(2-8 \%)[11,12]$, Arab (2-5\%) [13], African-American (2-4\%) [14], and Japanese $(0.4 \%)$ [15] populations. In the natives of South America, equatorial and southern Africa, and the Aboriginal people of Australia, HLA-B27 is virtually absent $[16,17]$. The prevalence of SpA corresponds to the distribution of HLA-B27 alleles in various populations.

A potential genetic susceptibility to ankylosing spondylitis (AS) was first recognized in 1950 [18] and the strong link to HLA-B27 was discovered in 1973 by two research groups $[19,20]$. AS is a radiographic axial SpA primarily with spinal and sacroiliac joint involvement, which is characterized by enthesitis with chronic inflammation, which subsequently results in fibrosis and ossification of the involved sites. HLA-B27 has the strongest association with AS among disease entities of the SpA group, especially in Caucasians, with $88-96 \%$ of patients being positive $[19,20]$. Asian AS patients carry HLA-B27 less frequently. Among African Americans, HLA-B27 is present in $50 \%$ of patients with AS [21]. Thirty to eighty percent of patients with reactive arthritis (ReA) and $20-35 \%$ of patients with psoriatic arthritis are HLA-B27 positive [22, 23].

Ethnic differences seem to exist regarding disease susceptibility conferred by HLA-B27. The relative risk of developing SpA in HLA-B27 positive individuals is increased 20-100-fold in the Caucasian population $[24,25,26]$, however, a study carried out on the Indonesian population found no increased relative risk among HLA-B27 positive subjects [27]. Ten to 30 percent of HLA-B27-positive first-degree relatives of HLA-B27-positive AS patients also develop the disease [28].

The risk of HLA-B27-positive individuals to develop ReA is 5-10 times greater than that of the general population [29]. The role of gene dosage is inconclusive. On one hand, higher relative risk of developing AS in HLA-B27 homozygotes was observed in Finnish AS patients. Interestingly, homozygous patients showed a less severe disease course [30]. On the other hand, an earlier study carried out in the Netherlands and a more recent study in Korea found no significant difference between homozygous and heterozygous patients [31, 32]. 


\section{Structure and Subtypes}

Similar to other MHC class I molecules, HLAB27 is a heterotrimer derived from a heavy chain encoded by the HLA genes, a $\beta 2$-microglobulin light chain and the presented peptide. HLA-B27 differs from other HLA-B molecules on possessing a free cysteine at residue 67 (Cys67) allowing the molecule to create stable homodimers without $\beta 2$-microglobulin due to the formation of disulfide bonds [33]. HLA-B27 shows a marked genotypic and phenotypic polymorphism with at least 132 alleles and 105 subtypes. Non-synonymous nucleotide substitutions affecting the antigen-binding cleft can lead to differences in antigen presentation and ultimately in disease association [34].

Furthermore, the frequency of HLA-B27 subtypes varies among different ethnic groups as well. One of the benefits of genetic HLA-B27 testing is that the different subtypes can be determined more reliably and reproducibly, all of which have different levels of associations with disease [35]. The $B^{\star} 27: 05$ subtype is the most common in Caucasians, other subtypes evolved from this ancestral type by gene conversion, reciprocal combination, and point mutation. It is, however, probably not linked to SpA in the African population. $B * 27: 02$ shows a strong association in the Mediterranean population, while $B^{\star} 27: 04$ is a common subtype in Asian SpA patients [36]. A recent meta-analysis composed of 8993 AS patients and 19,254 healthy controls confirmed the significant association of $\mathrm{B}^{\star} 27: 02$ and $\mathrm{B}^{\star 2} 27: 04$ with $\mathrm{AS}$. $B * 27: 03, * 27: 06$, and *27:09 are considered to be protective subtypes, although SpA cases in patients carrying these subtypes have been reported. $\mathrm{B}^{\star} 27: 03$ and $\mathrm{B} * 27: 06$ are common in Southeast Asia, while *27:09 is frequently found in Sardinia and Italy. Some rare subtypes also seem to contribute to the risk of SpA, including $B^{*} 27: 01, \quad B * 27: 07, \quad B * 27: 08, \quad B * 27: 10, \quad B * 27: 13$,

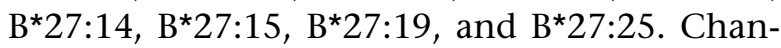
ges of the primary structure of the HLA-B27 protein may explain the different levels of disease associations, especially the variations affecting the antigen-binding cleft and as a consequence possibly the peptide specificity. There has been a difference of two amino acids observed between the $\mathrm{F}$ pockets of the peptide binding groove of $\mathrm{B}^{\star} 27: 06$ and $\mathrm{B}^{\star} 27: 04$, as well as a difference of one amino acid between $B^{\star} 27: 09$ and $B * 27: 05$. These minor changes of the amino acid sequences result in significantly different risk profiles [37, 38, 39, 40, 41].

\section{Contribution to Disease}

Despite intensive research in the last decades, the pathomechanism of SpA and the contribution of HLA-B27 to disease still remains unclear, as neither one of the existing hypotheses can fully describe and explain the underlying mechanisms.

It is, however, more than likely that the pathomechanism is more sophisticated than a single-not yet identified-self-antigen. While the molecular mimicry and arthritogenic peptides hypothesis presents a model compatible with classic autoimmunity, the unfolded protein response hypothesis as well as the cell surface HLA-B27 homodimers hypothesis rather support the autoinflammatory aspects of SpA.

The unfolded protein response hypothesis is based on the ability of HLA-B27 heavy chains to form stable homodimers owing to the free thiol groups of Cys67 [33]. These complexes are retained in the endoplasmic reticulum in the absence of $\beta 2$-microglobulin, misfold, and accumulate in the endoplasmic reticulum, leading to stress response and inflammation [42]. The protective $B^{\star 27: 06}$ and $B^{\star 27: 09}$ subtypes are less prone to misfolding than subtypes associated with disease risk. While this observation might seem to support this hypothesis, it is undermined by the fact that the disease-associated $B^{\star} 27: 07$ subtype has been shown to fold equally efficiently [43].

$\beta 2$-microglobulin-free HLA-B27 heavy chain homodimers can also be found on the cell membrane, where they can also interact with CD4-positive $\mathrm{T}$ lymphocytes, NK cells, and myelomonocytic cells that express killer-immunoglobulin-like receptors (KIR) and leukocyte immunglobulin-like receptors (LILR). $\beta 2$ microglobulin can also be released from HLAB27 molecules on the cell surface and be 
deposited in synovial tissue, suggesting a possible role in the pathogenesis of SpA [44].

The molecular mimicry and arthritogenic peptides hypothesis proposes that owing to the properties of the antigen-binding cleft HLA-B27 can present certain microbial peptides similar to self-antigens. The immune response triggered by the displayed microbial peptides causes HLAB27 restricted CD8-positive T-lymphocytes to cross-react with these arthritogenic peptides, triggering chronic inflammation [45]. Indeed, several such microbial peptides have been identified. The nitrogenase enzyme of Klebsiella pneumoniae shares a sequence of six consecutive amino acids with HLA-B27 [46]. Another $K$. pneumoniae protein, the pullulanase enzyme and certain outer surface proteins of Yersinia enterocolitica and pseudotuberculosis, Shigella flexneri and Salmonella typhimurium also possess sequences homologous with HLA-B27 [47, 48]. A recent study aiming to identify such arthritogenic peptides assessed the peptide repertoire of eight frequent HLA-B27 subtypes (HLA$B \star 27: 02-09)$. They identified more than 7500 endogenous peptides presented by these B27 subtypes. However, most peptides that are presented by the risk subtypes could also bind to $B^{\star} 27: 06$ and $B * 27: 09$, which are considered to be protective. This significant overlap of presented peptides between the subtypes leads the authors to the conclusion that the different risk profiles among subtypes may be due to quantitative changes affecting antigen sensitivity of autoreactive $\mathrm{T}$ cells and most likely not to qualitative changes of the HLA-B27 peptide repertoire [49]. Additionally, several studies proposed a link between the interaction of HLAB27 with the intestinal microbiome and the pathogenesis of related diseases. HLA-B27 may affect the composition of the gut flora. Indeed, dysbiotic changes have been described in patients with SpA. HLA-B27 transgenic rats had increased proportions of Prevotellaceae and loss of Rikenellaceae in the intestinal flora. If these HLA-B27 transgenic animals were kept in a germ-free environment, they did not develop arthritis. Recolonization of the gut with Bacteroides vulgatus resulted in inflammatory changes [50, 51]. However, introducing Lactobacillus and fusiform bacteria to the gut of germ-free animals had shown no such effect. These observations suggest that the modulation of the complex interplay between the immune system and microbiome can influence (and in some cases prevent) disease manifestation in this animal model. These changes might be connected with the unfolded protein response: the endoplasmic reticulum stress response could lead to intestinal inflammation, impaired barrier function, and loss of oral tolerance. The resulting increased translocation of microbial antigens could on one hand induce extraintestinal inflammation and on the other hand prime autoreactive T-lymphocytes [52, 53, 54]. However, a significant role of microbial antigens or arthritogenic peptides in the pathogenesis of SpA has not been unequivocally demonstrated.

\section{Clinical Relevance}

HLA-B27 determination has obtained clinical significance in the past decades in the routine diagnostic work-up of SpA due to its strong genetic association with disease. HLA-B27 determination has a sensitivity of $83-96 \%$, specificity of $90-96 \%$, and a likelihood ratio of 9.0 for AS in Caucasians with inflammatory back pain [55]. HLA-B27 positivity is part of the Assessment of Spondyloarthritis International Society (ASAS) classification criteria for axial and peripheral SpA as well as the Amor Criteria for diagnosis of SpA [56]. Current German guidelines also recommend HLA-B27 determination in case of clinical suspicion of SpA. However, screening of the general population is not recommended, as a positive result merely indicates genetic susceptibility. Accordingly, only a minority of HLA-B27 carriers will develop a disease of the SpA spectrum. Generally, testing for HLA-B27 should not be repeated, although in case of serological typing cross-reactivity with other HLA-B molecules as well as falsenegative results were reported $[57,58]$.

The data provided by the Recognising and Diagnosing Ankylosing Spondylitis Reliably (RADAR) study has lead to the development of a strategy for primary care physicians when to refer patients with early onset ( $<45$ years) 
chronic back pain to rheumatologic evaluation: the selection could be based on either HLA-B27 positivity, inflammatory back pain, or sacroiliitis on MRI. The authors concluded that a referral strategy based on these three criteria can lead to the diagnosis of axial SpA in 35\% of cases [59].

In addition to being a pivotal part of the diagnostic work-up, a prognostic value has been attributed to HLA-B27 as well. In patients with AS HLA-B27, positivity is associated with earlier disease onset, higher disease activity, risk of peripheral joint involvement, symmetric sacroiliitis, severity of MRI findings in sacroiliitis, and positive family history $[60,61,62,63]$, although there have been conflicting reports $[64,65]$. Undiagnosed patients with early inflammatory back pain-especially in case of non-radiologic axial SpA-benefit from the combination of MRI of the sacroiliac joints and HLA-B27 determination. Severe sacroiliitis in HLA-B27-positive patients is highly specific for the development of AS. Patients with mild or no sacroiliitis on MRI have a low risk of developing AS regardless of the HLA-B27 status [66]. Higher NSAID use and higher need for biologicals has been observed in HLA-B27-positive patients with AS [67]. On the other hand, TNF-alpha inhibitors show a greater therapeutic effect in HLA-B27-positive patients with AS [68, 69].

Psoriatic arthritis (PsA), a further entity of the SpA group, is a multifaceted chronic inflammatory joint disease, which is associated with cutaneous psoriasis in the majority of patients. It generally manifests as an asymmetrical oligoarthritis, although polyarticular as well as axial forms also commonly occur. In patients with PsA, HLA-B27 is associated with axial manifestation and possibly also with distal phalangeal joint involvement, and this association seems to be independent of psoriasis [70]. However, PsA is not associated with HLA-Cw6, which is present in $10-60 \%$ of patients with psoriasis [71], although earlier studies using serologic methods described a possible connection. Interestingly, $61 \%$ of PsA patients with symmetric sacroiliitis carried HLA-B ${ }^{\star} 27: 05$, as opposed to $9.8 \%$ of patients with asymmetric sacroiliitis, where the haplotype HLA-B*08:01$\mathrm{C}^{*}$ 07:01 was more prevalent.
Patients possessing $\mathrm{B}^{\star 27: 05}$ and especially the $B^{*} 27: 05-C^{*} 01: 02$ haplotype had a higher risk of dactylitis. The $B^{\star} 27: 05$ and $C^{\star} 01: 02$ alleles were associated with enthesitis in PsA.

Patients with a synovial-predominant pattern carried the $\mathrm{B}^{*} 08: 01-\mathrm{C}^{*} 07: 01$ haplotype more frequently, which predisposes to joint deformity. The $\quad B^{*} 27: 05-C^{*} 02: 02, \quad B * 37: 01-$ $C^{*} 06: 02$ and $B^{*} 08: 01-C^{*} 07: 01$ haplotypes are associated with a more severe disease course [72]. Therefore, the different MHC class I alleles play a role in determining whether the patients with PsA develop asymmetrical or symmetrical sacroiliitis as well as enthesitis and dactylitis.

Uveitis is strongly linked to HLA-B27 as well. Conversely, the presence of an isolated HLAB27-positive uveitis confers a high risk for developing SpA [73]. HLA B27 positivity correlates with worse prognosis and more severe disease course in ReA compared to B27-negative patients [74]. Therefore, the diagnostic role of HLA B27 is mostly to support the clinical suspicion of $\mathrm{SpA}$ in addition to providing prognostic information.

In addition to SpA, HLA-B27 has also been linked to other disease entities. Although rheumatoid arthritis is not associated with HLAB27 in itself, an elevated risk of atlanto-axial subluxation has been described in carriers [75].

HLA-B27 is also considered to have a protective role in several viral diseases such as HIV, hepatitis $\mathrm{C}$, influenza, Epstein-Barr virus, herpes simplex virus and Puumala hantavirus infection, although it increases the risk of contracting malaria $[76,77,78,5]$. Interestingly, a recent study reported the HLA-B27 molecule sharing a homology of four consecutive amino acids with an immunodominant peptide of E1 glycoprotein of Chikungunya virus. This leads the authors to the conclusion that HLA-B27 positivity might also play a role in persistent arthralgia following Chikungunya infection; its importance, however, remains to be seen [79].

Recent genome-wide associated studies performed in large groups of patients pinpointed the association of several non-B27 HLA as well as non-HLA genes with SpA $[80,81]$. Nevertheless, routine genetic testing of non-B27 HLA as part of the diagnostic work-up of SpA is likely premature [82]. 


\section{MHC CLASS I: HLA-B51 AND ADAMANTIADES-BEHÇET'S DISEASE (BD)}

Behçet's disease (BD) belongs to the group of variable vessel vasculitides according to the 2012 Revised International Chapel Hill Consensus Conference Nomenclature of Vasculitides, characterized by inflammatory eye disease (uveitis), oral and genital ulcers. Similarly to SpA, BD also shows a marked geographical distribution with Mediterranean and Asian populations being most affected, hence the name "Silk Road disease". The prevalence of BD is $17-42 / 10,000$ in Turkey, 2.1-420/100,000 in Asian and North African populations and $0.3-7.5 / 100,000$ in Western Europe and the United States [83, 84, 85].

Patients with BD often carry an MHC class I molecule, HLA-B51 [86], especially those of Turkish or Asian origin, whereas the association in Caucasian patients is weaker. In a recent meta-analysis, the prevalence of HLA-B51 in BD patients ranged between $50 \%$ and $72 \%$ [87] compared to $10-15 \%$ in healthy controls in high-risk populations.

Further genetic and environmental factors are likely to play an additional role in the pathogenesis of BD. A change of BD phenotype, in particular a decrease in HLA-B51 frequency, has recently been reported in Japanese patients, accordingly [88].

\section{Structure and Subtypes}

HLA-B51 is one of two distinct split-antigens of the HLA-B5 serotype and is primarily associated with $B D$ risk, although some case reports have also found a possible link with the second split-antigen, HLA-B52 [89, 90]. Several HLA-B51 subtypes have been described, of which especially $B * 51: 01$, $B \star 51: 02(01), B^{\star} 51: 08, B * 51: 09$, and $B^{\star} 51: 22$ seem to be associated with BD risk $[91,92]$.

\section{Contribution to Disease}

The role of HLA-B51 in the pathogenesis of BD is not fully understood. Selective binding of certain peptides and the activation of CD8positive T-lymphocytes and NK cells due to interactions of the HLA-B51-heterotrimer and T-cell receptors as well as killer immunoglobulin-like receptors are likely to be implicated. Gamma-delta $T$ cells also play a role in the pathogenesis of BD. Furthermore, active BD was associated with significant in vivo activation of V $\delta 1$ and V $\delta 2$ gamma-delta T-cells, while an overproportional activation of $\mathrm{V} \delta 1$ gammadelta T-cells has been seen exclusively in HLAB51 positive patients [93]. Additionally, a possible role of HLA-B51 in neutrophile hyperfunction in $\mathrm{BD}$ has been described. The spontaneous activation of HLA-B51-positive neutrophils leads to perivascular tissue injury and promotes a Th1 immune response $[94,95]$. These findings suggest that HLA-B51 is involved in the activation of CD8-positive T-cells, gamma-delta T-cells, NK-cells, and neutrophils.

\section{Clinical Relevance}

As for the clinical significance, HLA typing is not part of the International Criteria for Behçet disease, however, the testing is available in several medical laboratories. The estimated sensitivity is $51 \%$ and the specificity $71 \%$ [96]. It is important to understand the limitations and the diagnostic conclusiveness of both positive and negative results. It is not meant to diagnose $\mathrm{BD}$, but rather support the diagnosis. The screening of high-risk populations is not recommended, as the majority of HLA-B51 carriers do not develop BD. Conversely, BD can not be excluded in the absence of HLA-B51.

A possible prognostic value has been attributed to HLA-B51: HLA-B51 carriers have been shown to have a higher risk of genital ulcers as well as ocular or skin involvement. Male patients are more likely to be HLA-B51 positive [87]. Certain subtypes may be associated with different risk profiles, for example Turkish HLA$B \star 51: 03$-positive patients are at a higher risk of neurological involvement, and HLA-B ${ }^{\star 51: 09}$ may lower the risk of developing papulopustular lesions [92].

The testing of additional BD susceptibility HLA alleles, such as HLA-A03, A26, B15, 27, 57 
$[97,98]$, is currently not considered to be clinically or diagnostically relevant due to their low specificity.

\section{MHC CLASS II: HLA-DQ2/DQ8 AND CELIAC DISEASE (CD)}

Celiac disease (CD) is one of the most common organ-specific autoimmune diseases with a prevalence of $1 \%$ that primarily affects the small intestines following gluten exposure [99]. It has strong links to both genetic and environmental factors, the latter being gluten exposure. As for the genetic factors, a strong association exists with MHC class II alleles, HLA-DQ2, and DQ8. A link with non-MHC genes has also been described in genome-wide association studies [100, 101].

\section{Subtypes and Contribution to Disease}

Ninety percent of Caucasian patients with CD express HLA-DQ2.5cis encoded by HLADQA1*0501-DQB1*0201 or DQ2.5trans on HLA-DQA1*0505 DQB1*0301/DQA1*0201DQB $1{ }^{*} 0202$ haplotypes. Five percent of these patients carry HLA-DQ8 with the HLADQA $1{ }^{*} 0301-\mathrm{DQB} 1{ }^{*} 0302$ haplotype. Patients negative for these HLA molecules mostly possess HLA-DQA $1{ }^{*} 0201-\mathrm{DQB} 1{ }^{*} 0202$ haplotypes (HLA-DQ2.2) [102]. HLA-DQ2.2 carriers have an inconsequential risk of developing $\mathrm{CD}$. In contrast, approximately $20-30 \%$ of the healthy Caucasian population is HLA-DQ2 positive. A gender-specific distribution of HLA alleles has been described: female patients with celiac disease are infrequently DQ2.5/DQ8-negative.

However, not all DQ2 carriers develop CD. Non-HLA genes are likely to play an additional role, as seen in identical twins, who show a higher concordance rate (70\%) than HLA identical siblings. HLA-DQ2 or -DQ8 are necessary, but not sufficient for the development of CD. The estimated risk of DQ2/DQ8 carriers is 36-53\% [103].

Zygosity is a strong determinant of gluten peptide presentation and disease risk. Additionally, homozygous patients have been shown to have a more severe disease course. Especially HLA-DQ2.5 homozygotes may exhibit an augmented immune response following infections of the gastrointestinal tract due to elevated interferon gamma concentrations, which has been shown to regulate HLA-DQ expression indirectly [104, 105].

Different haplotypes recognize different ligands with different affinity, resulting in different risk profiles. A comparison of DQ2.5-ligands with DQ2.2-ligands revealed that DQ2.5 can present a broader spectrum of gliadin peptides than DQ2.2. Gliadin peptides can withstand gastrointestinal digestion, therefore, DQ2-molecules can recognize these resistant immunodominant epitopes and present them to CD4-positive T-lymphocytes in the intestinal mucosa. The affinity of DQ2 to gliadin peptides is further increased by the tissue transglutaminase enzyme, which deamidates glutamine residues of gliadin peptides. The resulting glutamic acid residues display an increased affinity to DQ2 molecules [106, 107]. The activation of both the innate and adaptive immune system leads to a humoral response against tissue transglutaminase, as well as to TNF alpha and interferon gamma secretion, which ultimately result in tissue damage and disease manifestations.

Additionally, possible links with infections have been described. Due to a homology of an amino acid sequence between the $54 \mathrm{kDa} \mathrm{E} 1 \mathrm{~b}$ protein of human adenovirus type 12 and gliadin, exposure to the virus may promote autoimmunity in genetically susceptible individuals [108]. Hepatitis C, Giardia lamblia, Campylobacter jejuni, Rotavirus and Enterovirus have also been implicated as possible triggers of CD. It has been postulated that HLA-DQ molecules may also have an impact on the intestinal microbiome. Patients with celiac disease have a different composition of the intestinal microbiome with decreased proportion of Actinobacteria (especially Bifidobacterium genus) and elevated proportion of Firmicutes, Proteobacteria and Staphylococcus spp. [109, 110]. There is a permanent interaction between microbes and Th17, Treg, and B-lymphocytes. HLA-DQ molecules are likely to influence this interaction depending on the displayed ligands 
and lead to either tolerance of certain microbial strains or immune response against them. It is therefore possible that the effect of HLA molecules on the pathogenesis of celiac disease may be to some extent due to the altered microbiome.

\section{Clinical Relevance}

Regarding the clinical and diagnostic relevance, the testing of DQ2/DQ8 has an excellent negative predictive value of $99 \%$ : a negative test virtually excludes CD [111], while a positive test merely indicates genetic susceptibility. An advantage of HLA testing is that a gluten-free diet is not necessary for optimal diagnostic conclusiveness in marked contrast to autoantibody testing and histology [112].

According to the European Society for Pediatric Gastroenterology, Hepatology, and Nutrition guidelines for the diagnosis of celiac disease testing of HLA-DQ2/DQ8 should be included in the diagnostic work-up of celiac disease in children. Small-bowel biopsy may not be necessary in the pediatric population in case of symptomatic patients with significantly elevated tTG and EMA antibody titers and HLADQ2/DQ8 positivity [113].

A similar straightforward approach has been suggested for all age groups with suspected CD. This so-called "four out of five rule" allows the diagnosis of $\mathrm{CD}$ if four of the following five criteria are met: typical symptoms, significant elevation of CD antibodies, HLA-DQ2 or HLADQ8, typical biopsy result, response to glutenfree diet [114].

US Guidelines do not recommend HLA-DQ2/ 8 testing in the routine diagnostic work-up of $\mathrm{CD}$, however, it may be useful in selected clinical situations, such as a discrepancy between histologic and serologic results [115].

HLA testing may also be useful to exclude CD in high-risk individuals, such as first-degree relatives of CD patients, patients with autoimmune diabetes mellitus, selective IgA deficiency, Down syndrome, Turner syndrome, Williams syndrome, or autoimmune thyroiditis. Testing could also be considered in case of unexplained iron deficiency anemia or early onset osteoporosis $[116,117]$. With the help of HLA testing, the number of invasive diagnostic procedures may be reduced in this high-risk population.

\section{MHC CLASS II: HLA-DRB1, SHARED EPITOPE HYPOTHESIS, AND RHEUMATOID ARTHRITIS (RA)}

Rheumatoid arthritis (RA) is a common chronic systemic autoimmune disease, which primarily presents with a symmetrical polyarthritis and has a prevalence of $0.5-1 \%$ worldwide [118]. Although the exact pathogenesis of RA remains unclear, its complex association with MHC class II molecules has been described [119]. The contribution of HLA genes to susceptibility is estimated to account for 50\% of risk [120].

Remarkably, RA seems to be associated with such HLA-DRB1 alleles, which share sequences of five amino acids in position $70-74$ of the antigen-binding groove of HLA-DR- $\beta$-chains, as described by the shared epitope hypothesis $[121,122]$. The shared epitopes (for example QKRAA, QRRAA, RKRAA, RRRAA) are present in 70-90\% of Caucasian patients with seropositive RA in contrast to the prevalence of $20-30 \%$ in the general population and patients with seronegative RA [123]. The highest relative risk of developing RA has been attributed to HLADRB ${ }^{*} 0401$ and ${ }^{*} 0404$, which can be detected in $50-61 \%$ and $27-37 \%$ of seropositive patients, respectively. DRB1*0404 may also be associated with seronegative RA. The Latter population also exhibits HLA-DRB ${ }^{*} 0101$ [124, 125]. The HLA-DRB ${ }^{*} 0401 /{ }^{*} 0404$ genotype is associated with elevated risk of disease, earlier onset, seropositivity, accelerated joint damage and the presence of rheumatoid nodules [126]. Ethnic differences have been reported, the prevalence of DRB-1 in African-American patients is lower (25\%) [127]. HLA-DRB1*0405 is the most frequent allele in Asian RA patients [127, 128]. HLA-DRB1*1402 is associated with RA in Native American patients [127]. A large European meta-analysis has shown that HLA-DRB1*13:01 provides protection against anti-citrullinated protein antibodies (ACPA)-positive disease but not against ACPA-negative RA [129]. 
Homozygosity or compound heterozygosity for HLA-DRB1 alleles containing one of the shared epitope sequences is associated with increased risk of developing RA. Patients carrying two shared epitope-containing HLADRB1*04 alleles-especially homozygosity for HLA-DRB1*0401-have a higher risk of extraarticular manifestations including rheumatoid vasculitis [130].

\section{Contribution to Disease}

Several theories of the pathogenetic role of the shared epitopes have been proposed such as molecular mimicry, antigen presentation of arthritogenic peptides, as well as a role in the positive selection of specific autoreactive T-lymphocytes in the thymus. However, the exact mechanisms remain unclear.

Recent studies have shown that polymorphisms in certain amino acid positions of MHC molecules can better account for genetic susceptibility than solely the shared epitope hypothesis. Amino acids in positions 11, 13, 70, 71 , and 74 of the DR- $\beta$ chain show strong independent correlation with relative risk. Interestingly, only changes of the latter three affect the shared epitope motif. Positions 70 and 71 have a significant role in presentation of vimentin, alpha-enolase, and collagen as well as in modulating the interaction with $\mathrm{T}$-cell receptors [131]. Positions 67 and 86 may also affect the binding of possible arthritogenic peptides [132]. It has been suggested that three of the above-mentioned amino acid positions within HLA-DRB1 $(11 / 13,71,74)$ and in two non-DRB-1 HLA (position 9 of HLA-B, position 9 of HLA-DPB1) account for the majority of HLA-associated genetic susceptibility to RA [133]. HLA-DRB1 haplotypes also influence disease severity, mortality, and therapy response.

Valine in amino acid position 11 of HLADRB1 has the strongest genetic association with radiologic damage independent of shared epitope status as well as with clinical and laboratory markers of inflammation and overall mortality. Positions 71 and 74 are also associated with erosive damage [134, 135]. These findings underline the additional importance of non-shared epitope polymorphisms.

Shared epitopes are associated significantly only with ACPA-positive RA [136]. Citrullinated antigens bind preferentially to HLA-DRB1 with shared epitope sequences leading to the activation of autoreactive T-cells and subsequently to the expansion of autoantibody-secreting B-lymphocytes. Patients carrying shared epitope motifs were more frequently ACPA positive in a dosage-dependent manner. Cigarette smoking, a major environmental risk factor of RA, has been shown to induce citrullination of proteins in the lung and its harmful effect may be due to interactions with HLA-DRB1 molecules and trigger the excessive immune reaction [137]. Indeed, heavy smoking increased risk of developing ACPA-positive RA in the presence of shared epitope-containing HLA-DRB1 alleles, although no significant association has been found in patients with ACPA-negative RA $[138,139]$.

\section{Clinical Relevance}

Regarding the clinical usefulness of genetic testing in patients with suspected or diagnosed RA HLA-DRB1 analysis is neither included in current classification criteria nor recommended as a diagnostic tool by current ACR/EULAR guidelines [140].

In a case-control study HLA-DRB1*0401 and ${ }^{*} 0404$ had a sensitivity of $60 \%$ and a specificity of $64 \%$ as indicators for the future development of RA. The combination of anti-CCP2 antibodies and the testing of these two HLA-haplotypes proved to be the best approach for detecting RA susceptibility [141]. Other authors found no benefit of additional shared epitope testing owing to its strong association with ACPA [142].

Genotyping of shared epitopes and HLADRB1 variants may provide valuable information regarding the choice of treatment options. A triple therapy containing methotrexate, hydroxychloroquine, and sulfasalazine is more effective in the presence of shared epitopes than methotrexate monotherapy. No significant difference between therapy regimes was observed, however, in shared epitope-negative patients 
[143]. The efficacy of TNF-alpha inhibitors may also be influenced by HLA-DRB1 haplotypes. TNFi response was not associated with the presence of shared epitopes but rather with amino acid position 11. Patients with valine at this position had significantly better EULAR responses independent of zygosity and ACPA status compared to noncarriers $[134,144]$.

\section{CONCLUSIONS}

In concluding this section, it should be reemphasized in light of current evidence that the contribution of HLA-DRB1 to RA susceptibility is far weaker than those of HLA-DQ2/DQ8 to CD or HLA-B27 to SpA, respectively. Nevertheless, HLA-DRB1 analysis is available in several commercial medical laboratories. Results should be interpreted with caution: on one hand a positive result merely indicates genetic predisposition and is not suitable for the diagnosis of RA. On the other hand, RA can certainly not be excluded in case of absence of shared epitopes, especially in non-Caucasian patients.

\section{ACKNOWLEDGEMENTS}

Funding. No funding or sponsorship was received for this study or publication of this article.

Authorship. All named authors meet the International Committee of Medical Journal Editors (ICMJE) criteria for authorship for this article, take responsibility for the integrity of the work as a whole, and have given their approval for this version to be published.

Disclosures. Gergely Bodis, Victoria Toth, and Andreas Schwarting have nothing to disclose.

Compliance with Ethics Guidelines. This article is based on previously conducted studies and does not contain any studies with human participants or animals performed by any of the authors.

Open Access. This article is distributed under the terms of the Creative Commons Attribution-NonCommercial 4.0 International License (http://creativecommons.org/licenses/ by-nc/4.0/), which permits any noncommercial use, distribution, and reproduction in any medium, provided you give appropriate credit to the original author(s) and the source, provide a link to the Creative Commons license, and indicate if changes were made.

\section{REFERENCES}

1. Reveille JD. Epidemiology of spondyloarthritis in North America. Am J Med Sci. 2011;341(4):284-6.

2. Stolwijk C, Boonen A, Tubergen AV, Reveille JD. Epidemiology of spondyloarthritis. Rheum Dis Clin North Am. 2012;38(3):441-76.

3. Rohekar S, Pope J. Assessment of work disability in seronegative spondyloarthritis. Clin Exp Rheumatol. 2010;28:35-40.

4. Ramonda R, Marchesoni A, Carletto A, et al. Patientreported impact of spondyloarthritis on work disability and working life: the ATLANTIS survey. Arthritis Res Ther. 2016;18:78.

5. Mathieu A, Cauli A, Fiorillo MT, et al. HLA-B27 and ankylosing spondylitis geographic distribution versus malaria endemic: casual or causal liaison? Ann Rheum Dis. 2008;67:138-40.

6. Richens JE, Prasad ML, Bhatia K, Tung M. Arthritis and HLA-B27 in Papua New Guinea. Br Med J. 1986;293(6556):1209 (Clinical research ed).

7. Bhatia $\mathrm{K}$, et al. High prevalence of the haplotype HLA-A11, B27 in arthritis patients from the highlands of Papua New Guinea. Tissue Antigens. 1988;31(2):103-6.

8. Gofton JP, Chalmers A, Price GE, Reeve CE. HL-A 27 and ankylosing spondylitis in B.C. Indians. J Rheumatol. 1984;11(5):572-3.

9. Boyer GS, Templin DW, Cornoni-Huntley JC, Everett DF, Lawrence RC, Heyse SF, Miller MM, Goring WP. Prevalence of spondyloarthropathies in Alaskan Eskimos. J Rheumatol. 1994;21(12):2292-7. 
10. Erdesz S, et al. Spondyloarthropathies in circumpolar populations of Chukotka (Eskimos and Chukchi): epidemiology and clinical characteristics. J Rheumatol. 1994;21(6):1101-4.

11. Liu X, et al. High frequencies of HLA-B27 in Chinese patients with suspected of ankylosing spondylitis. Rheumatol Int. 2010;30(10):1305-9.

12. Ho HH, Chen JY. Ankylosing spondylitis: Chinese perspective, clinical phenotypes, and associated extra-articular systemic features. Curr Rheumatol Rep. 2013;15:344.

13. Mustafa KN, Hammoudeh M, Khan MA. HLA-B27 Prevalence in Arab populations and among patients with ankylosing spondylitis. J Rheumatol. 2012;39:1675-7.

14. Khan MA. Race-related differences in HLA association with ankylosing spondylitis and Reiter's disease in American blacks and whites. J Natl Med Assoc. 1978;70(1):41-2.

15. Tanaka H, Akaza T, Juji T. Report of the Japanese Central Bone Marrow Data Center. Clin transplant. 1996;10:139-44.

16. Khan MA. HLA-B27 and its subtypes in world populations. Curr Opin Rheumatol. 1995;7:263-9.

17. Tikly M, Njobvu P, McGill P. Spondyloarthritis in Sub Saharan Africa. Curr Rheumatol Rep. 2014;16(6):421.

18. Riecker $\mathrm{HH}$, et al. The inheritance of spondylitis rhizomelique (ankylosing spondylitis) in the $\mathrm{K}$. family. Ann Intern Med. 1950;33(5):1254-73.

19. Schlosstein L, Terasaki PI, Bluestone R, Pearson CM. High association of an HL-A antigen, W27, with ankylosing spondylitis. N Engl J Med. 1973;288:704-6.

20. Brewerton DA, et al. Ankylosing spondylitis and HLA 27. Lancet. 1973;1(7809):904-7.

21. Akkoc N, Khan MA (2006) Epidemiology of ankylosing spondylitis and related spondyloarthropathies. In: Weisman $\mathrm{MH}$, Reveille JD, van der Heijde D, editors. Ankylosing spondylitis and the spondyloarthropathies. Elsevier, p 117-131.

22. Kopplin LJ, et al. Review for disease of the year: epidemiology of HLA-B27 associated ocular disorders. Ocul Immunol Inflamm. 2016;24(4):470-5.

23. Queiro R, et al. HLA-B27 and psoriatic disease: a modern view of an old relationship. Rheumatology (Oxford). 2016;55(2):221-9.

24. Braun JBM, Remlinger G. Prevalence of spondylarthropathies in HLA-B27 positive and negative blood donors. Arthritis Rheumatol. 1998;41(1):58-67.

25. Reveille JD, et al. The prevalence of HLA-B27 in the US: data from the US National Health and Nutrition Examination Survey, 2009. Arthritis Rheumatol. 2012;64(5):1407-11.

26. Costantino F, et al. Prevalence of spondyloarthritis in reference to HLA-B27 in the French population: results of the GAZEL cohort. Ann Rheum Dis. 2013;74(4):689-93.

27. Nasution AR, Mardjuadi A, Suryadhana NG, et al. Higher relative risk of spondyloarthropathies among B27 positive Indonesian Chinese than native Indonesians. J Rheumatol. 1993;20:988-90.

28. van der Linden $\mathrm{S}$, et al. The risk of developing ankylosing spondylitis in HLA-B27 positive individuals: a family and population study. $\mathrm{Br} \mathrm{J}$ Rheumatol. 1983;22(4 Suppl 2):18-9.

29. Feltkamp TE. Factors involved in the pathogenesis of HLA-B27 associated arthritis. Scand J Rheumatol. 1995;101:213-7.

30. Jaakkola E, Herzberg I, Laiho K, et al. Finnish HLA studies confirm the increased risk conferred by HLAB27 homozygosity in ankylosing spondylitis. Ann Rheum Dis. 2006;65(6):775-80.

31. van Der Linden SM, Valkenburg HA, De Jongh BM, Cats A. The risk of developing ankylosing spondylitis in HLA-B27 positive individuals. a comparison of relatives of spondylitis patients with the general population. Arthritis Rheum. 1984;27(3):241-9.

32. Kim TJ, Na KS, Lee HJ, Lee B, Kim TH. HLA-B27 homozygosity has no influence on clinical manifestations and functional disability in ankylosing spondylitis. Clin Exp Rheumatol. 2009;27:574-9.

33. Dangoria NS, DeLay ML, Kingsbury DJ, Mear JP, Uchanska-Ziegler B, Ziegler A, Colbert RA. HLA-B27 misfolding is associated with aberrant intermolecular disulfide bond formation (dimerization) in the endoplasmic reticulum. J Biol Chem. 2002;277:23459-68.

34. Khan MA. Polymorphism of HLA-B27: 105 subtypes currently known. Curr Rheumatol Rep. 2013;15:362.

35. Frankenberger B, et al. Routine molecular genotyping of HLA-B27 in spondyloarthropathies overcomes the obstacles of serological typing and reveals an increased B *2702 frequency in ankylosing spondylitis. J Rheumatol. 1997;24(5):899-903. 
36. Lin J, et al. Ankylosing spondylitis and heterogeneity of HLA-B27 in Chinese. Chin Med J (Engl). 1996;109(4):313-6.

37. Taurog DJ. The mystery of HLA B27: if it isn't one thing, it's another. Arthritis Rheum. 2007;56(8):2478-81.

38. Hill AVS, Allsop CEM, Kwiatkowski D, Antsey NM, Greenwood BM, McMichael AJ. HLA class I typing by PCR: HLA-B27 and an African B27 subtype. Lancet. 1991;337:640-2.

39. Cauli A, et al. HLA-B* 2709 and lack of susceptibility to sacroiliitis: further support from the clinic. Clinical and Experimental Rheumatology. 2008;26(6):1111-2.

40. Yang T, Duan Z, Wu S, Liu S, Zeng Z, Li G, et al. Association of HLA-B27 genetic polymorphisms with ankylosing spondylitis susceptibility worldwide: a meta-analysis. Mod Rheumatol. 2014;24(1):150-61.

41. Lin $\mathrm{H}$, et al. Association of HLA-B27 with ankylosing spondylitis and clinical features of the HLA-B27associated ankylosing spondylitis: a meta-analysis. Rheumatol Int. 2017;37(8):1267-80.

42. Mear JP, Schreiber KL, Munz C, Zhu X, Stevanovic S, Rammensee HG, et al. Misfolding of HLA-B27 as a result of its $B$ suggests a novel mechanism for its role in susceptibility to spondyloarthropathies. J Immunol. 1999;163(12):6665-70.

43. Galocha B, López de Castro JA. Folding of HLA-B27 subtypes is determined by the global effect of polymorphic residues and shows incomplete correspondence to ankylosing spondylitis. Arthritis Rheumatol. 2008;58:401-12.

44. Sheehan NJ. HLA-B27: what's new? Rheumatology (Oxford). 2010;49:621-31.

45. Ebringer A. The cross-tolerance hypothesis, HLAB27 and ankylosing spondylitis. Br J Rheumatol. 1983;22(4 Suppl 2):53-66.

46. Schwimmbeck PL, Oldstone MB. Molecular mimicry between human leukocyte antigen B27 and Klebsiella. Consequences for spondyloarthropathies. Am J Med. 1988;85(6A):51-3.

47. Lahesmaa $\mathrm{R}$, et al. Molecular mimickry between HLA B27 and Yersinia, Salmonella, Shigella and Klebsiella within the same region of HLA $\alpha 1$-helix. Clin Exp Immunol. 1991;86:399-404.

48. Fielder M, et al. Molecular mimicry and ankylosing spondylitis: possible role of a novel sequence in pullulanase of Klebsiella pneumoniae. FEBS Lett. 1995;369:243-8.
49. Schittenhelm RB, et al. Revisiting the arthritogenic peptide theory: quantitative not qualitative changes in the peptide repertoire of HLA-B27 allotypes. Arthritis Rheumatol. 2015;67:702-13.

50. Hoentjen F, Tonkonogy SL, Qian BF, Liu B, Dieleman LA, et al. CD4(+) T lymphocytes mediate colitis in HLA-B27 transgenic rats monoassociated with nonpathogenic Bacteroides vulgatus. Inflamm Bowel Dis. 2007; 13:317-24.

51. Rath HC, Wilson KH, Sartor RB. Differential induction of colitis and gastritis in HLA-B27 transgenic rats selectively colonized with Bacteroides vulgatus or Escherichia coli. Infect Immun. 1999;67:2969-74.

52. Taurog JD, Richardson JA, Croft JT, Simmons WA, Zhou M, Fernandez-Sueiro JL, et al. The germfree state prevents development of gut and joint inflammatory disease in HLA-B27 transgenic rats. J Exp Med. 1994;180(6):2359-64.

53. Costello ME, et al. Microbes, the gut and ankylosing spondylitis. Arthritis Res Ther. 2013;15:214.

54. Lin $\mathrm{P}$, Bach M, Asquith M, Lee AY, Akileswaran L, Stauffer P, et al. HLA-B27 and human $\beta 2$-microglobulin affect the gut microbiota of transgenic rats. PLoS One. 2014;9:e105684.

55. Rudwaleit M, van der Heijde D, Khan MA, Braun J, Sieper J. How to diagnose axial spondyloarthritis early. Ann Rheum Dis. 2004;63(5):535-43.

56. Rudwaleit M, van der Heijde D, Landewe R, Listing J, Akkoc N, Brandt J, Braun J, Chou CT, CollantesEstevez E, Dougados M, et al. The development of Assessment of SpondyloArthritis international Society classification criteria for axial spondyloarthritis (part II): validation and final selection. Ann Rheum Dis. 2009;68(6):777-83.

57. Kirveskari J, et al. False-negative serological HLAB27 typing results may be due to altered antigenic epitopes and can be detected by polymerase chain reaction. Br J Rheumatol. 1997;36(2):185-9.

58. Levering WH, Wind $\mathrm{H}$, Sintnicolaas $\mathrm{K}$, et al. Flow cytometric HLA-B27 screening: cross-reactivity patterns of commercially available anti-HLA-B27 monoclonal antibodies with other HLA-B antigens. Cytom Part B Clin Cytom. 2003;54:28-38.

59. Sieper J, Srinivasan S, Zamani O, et al. Comparison of two referral strategies for diagnosis of axial spondyloarthritis: the Recognising and Diagnosing Ankylosing Spondylitis Reliably (RADAR) study. Ann Rheum Dis. 2013;72:1621-7.

60. Linssen A, Feltkamp TE. B27 positive diseases versus B27 negative diseases. Ann Rheum Dis. 1988;47(5):431-9. 
61. Feldtkeller E, Khan MA, van der Heijde D, van der Linden S, Braun J. Age at disease onset and diagnosis delay in HLA-B27 negative vs. positive patients with ankylosing spondylitis. Rheumatol Int. 2003;23:61-6.

62. Marzo-Ortega H, McGonagle D, O'Connor P, et al. Baseline and 1-year magnetic resonance imaging of the sacroiliac joint and lumbar spine in very early inflammatory back pain. Relationship between symptoms, HLA-B27 and disease extent and persistence. Ann Rheum Dis. 2009;68:1721-7.

63. Chung HY, Machado P, van der Heijde D, D'Agostino MA, Dougados M. HLA-B27 positive patients differ from HLA-B27 negative patients in clinical presentation and imaging: results from the DESIR cohort of patients with recent onset axial spondyloarthritis. Ann Rheum Dis. 2011;70:1930-6.

64. Khan MA, Kushner I, Braun WE. Comparison of clinical features in HLA-B27 positive and negative patients with ankylosing spondylitis. Arthritis Rheum. 1977;20:909-12.

65. Hamersma J, et al. Is disease severity in ankylosing spondylitis genetically determined? Arthritis Rheum. 2001;44:1396-400.

66. Bennett AN, et al. Severity of baseline magnetic resonance imaging-evident sacroiliitis and HLA-B27 status in early inflammatory back pain predict radiographically evident ankylosing spondylitis at eight years. Arthritis Rheumatol. 2008;58:3413-8.

67. Freeston J, Barkham N, Hensor E, Emery P, Fraser A. Ankylosing spondylitis, HLA-B27 positivity and the need for biologic therapies. Joint Bone Spine. 2007;74(2):140-3.

68. Rudwaleit M, Listing J, Brandt J, et al. Prediction of a major clinical response(BASDAI 50) to tumour necrosis factor alpha blockers in ankylosing spondylitis. Ann Rheum Dis. 2004;63:665-70.

69. Vastesaeger N, Van Der Heijde D, Inman R, Wang Y, Deodhar A, Hsu B, et al. Predicting the outcome of ankylosing spondylitis therapy. Ann Rheum Dis. 2011;70:973-81.

70. Brewerton DA, Caffrey M, Nicholls A, et al. HL-A 27 and the arthropathies associated with ulcerative colitis and psoriasis. Lancet. 1974;1:956-8.

71. Guðjónsson JE, Valdimarsson H, Kárason A, Antonsdóttir AA, Rúnarsdóttir EH, Gulcher JR, Stefánsson K. HLA-Cw6-positive and HLA-Cw6-negative patients with psoriasis vulgaris have distinct clinical features. J Investig Dermatol. 2002;118:362-5.
72. FitzGerald O, Haroon M, Giles JT, Winchester R. Concepts of pathogenesis in psoriatic arthritis: genotype determines clinical phenotype. Arthritis Res Ther. 2015;17(1):115.

73. Rosenbaum JT. Acute anterior uveitis and spondyloarthropathies. Rheum Dis Clin North Am. 1992;18:143-51.

74. Schiellerup P, Krogfelt KA, Locht H. A comparison of self-reported joint symptoms following infection with different enteric pathogens: effect of HLA-B27. J Rheumatol. 2008;35(3):480-7.

75. Ollier W, Pepper L, Thomson W. HLA-B27 as a marker for developing subluxations of the cervical spine in RA. Arthritis Rheumatol. 1994;37(suppl):A1017.

76. den Uyl D, van der Horst-Bruinsma IE, van Agtmael M. Progression of HIV to AIDS: a protective role for HLA-B27? AIDS Rev. 2004;6(2):89-96.

77. Mustonen J, et al. Association of HLA B27 With Benign clinical course of nephropathia epidemica caused by puumala hantavirus. Scand J Immunol. 1998;47(3):277-9.

78. Neumann-Haefelin C. HLA-B27-mediated protection in HIV and hepatitis $C$ virus infection and pathogenesis in spondyloarthritis: two sides of the same coin? Curr Opin Rheumatol. 2013;25:426-33.

79. Reddy V, et al. Molecular mimicry between Chikungunya virus and host components: a possible mechanism for the arthritic manifestations. PLoS Negl Trop Dis. 2017;11(1):e0005238.

80. Australo-Anglo-American Spondyloarthritis Consortium (TASC), Reveille JD, Sims AM, et al. Genome-wide association study of ankylosing spondylitis identifies non-MHC susceptibility loci. Nat Genet. 2010;42(2):123-7.

81. International Genetics of Ankylosing Spondylitis Consortium (IGAS) Cortes A, Hadler J, Pointon JP, Robinson PC, Karaderi $\mathrm{T}$, et al. Identification of multiple risk variants for ankylosing spondylitis through high-density genotyping of immune-related loci. Nat Genet. 2013;45(7):730-8.

82. Reveille JD. Biomarkers for diagnosis, monitoring of progression, and treatment responses in ankylosing spondylitis and axial spondyloarthritis. Clin Rheumatol. 2015;34:1009-18.

83. Azizlerli G, Kose AA, Sarica R, Gül A, Tutkun IT, Kulaç $M$, et al. Prevalence of Behçet's disease in Istanbul, Turkey. Int J Dermatol. 2003;42:803-6.

84. Mahr A, Belarbi L, Wechsler B, Jeanneret D, Dhote R, Fain O, Lhote F, Ramanoelina J, Coste J, Guillevin 
L. Population-based prevalence study of Behçet's disease: differences by ethnic origin and low variation by age at immigration. Arthritis Rheumatol. 2008;58(12):3951-9.

85. Çölgeçen E, Özyurt K, Ferahbaş A, Borlu M, Kulluk $\mathrm{P}$, Öztürk A, et al. The prevalence of Behçet's disease in a city in Central Anatolia in Turkey. Int J Dermatol. 2015;54:286-9.

86. Ohno S, et al. Close association of HLA-Bw51 with Behçet's disease. Arch Ophthalmol. 1982;100:1455-8.

87. Maldini C, Lavalley MP, Cheminant M, et al. Relationships of HLA-B51 or B5 genotype with Behçet's disease clinical characteristics: systematic review and meta-analyses of observational studies. Rheumatology (Oxford). 2012;51(5):887-900.

88. Kirino $\mathrm{Y}$, et al. Continuous evolution of clinical phenotype in 578 Japanese patients with Behçet's disease: a retrospective observational study. Arthritis Res Ther. 2016;18:217.

89. Sugisaki K, et al. HLA-B52-positive vasculo-Behçet disease: usefulness of magnetic resonance angiography, ultrasound study, and computed tomographic angiography for the early evaluation of multiarterial lesions. Mod Rheumatol. 2005;15(1):56-61.

90. Arber N, Klein T, Meiner Z, Pras E, Weinberger A. Close association of HLA-B51 and B52 in Israeli patients with Behçet's syndrome. Ann Rheum Dis. 1991;50:351-3.

91. Verity DH, Wallace GR, Vaughan RW, Stanford MR. Behçet's disease: from Hippocrates to the third millennium. Br J Ophthalmol. 2003;87:1175-83.

92. Demirseren DD, Ceylan GG, Akoglu G, et al. HLAB51 subtypes in Turkish patients with Behçet's disease and their correlation with clinical manifestations. Genet Mol Res. 2014;13:4788-96.

93. Yasouka $\mathrm{H}$, et al. Preferential activation of circulating CD8 + and $\gamma \delta \mathrm{T}$ cells in patients with active Behçet's disease and HLA-B51. Clin Exp Rheumatol. 2008;26(50):S59-63.

94. Takeno $M$, et al. Excessive function of peripheral blood neutrophils from patients with Behçet's disease and from HLA-B51 transgenic mice. Arthritis Rheum. 1995;38:426-33.

95. Eksioglu-Demiralp E, Direskeneli H, Kibaroglu A, Yavuz S, Ergun T, Akoglu T. Neutrophil activation in Behçet's disease. Clin Exp Rheumatol. 2001;19(5 Suppl 24):S19-24.
96. International Team for the Revision of the International. Criteria for Behçet's Disease (ITR-ICBD). The International Criteria for Behçet's Disease (ICBD): a collaborative study of 27 countries on the sensitivity and specificity of the new criteria. J Eur Acad Dermatol Venereol. 2014;28:338-47.

97. Kuranov $A B$, et al. Behçet's disease in HLA-B ${ }^{\star} 51$ negative Germans and Turks shows association with HLA-Bw4-80I. Arthritis Res Ther. 2014;16(3):R116.

98. Ortiz-Fernández L, Carmona F-D, Montes-Cano M-A, et al. Genetic analysis with the immunochip platform in Behçet disease. Identification of residues associated in the HLA class I region and new susceptibility loci. PLoS One. 2016;11(8):e0161305.

99. Gujral N, Freeman HJ, Thomson AB. Celiac disease: prevalence, diagnosis, pathogenesis and treatment. World J Gastroenterol. 2012;18:6036-59.

100. van Heel DA, Franke L, Hunt KA, Gwilliam R, Zhernakova $\mathrm{A}$, Inouye $\mathrm{M}$, et al. A genome-wide association study for celiac disease identifies risk variants in the region harboring IL2 and IL21. Nat Genet. 2007;39:827-9.

101. Garner C, Ahn R, Ding YC, Steele L, Stoven S, Green $\mathrm{PH}$, et al. Genome-wide association study of celiac disease in North America confirms FRMD4B as new celiac locus. PLoS One. 2014;9(7):101428 (Epub 2014/07/08).

102. Karell K, Louka AS, Moodie SJ, Ascher H, Clot F, Greco L, Ciclitira PJ, Sollid LM. Partanen J; European Genetics Cluster on Celiac Disease. HLA types in celiac disease patients not carrying the DQA $1^{*} 05$ DQB1*02 (DQ2) heterodimer: results from the European Genetics Cluster on Celiac Disease. Hum Immunol. 2003;64:469-77.

103. Fasano A. Genetics of celiac disease. http:// emedicine.medscape.com/article/1790189-overview. Updated November 10, 2016.

104. Vader W, et al. The HLA-DQ2 gene dose effect in celiac disease is directly related to the magnitude and breadth of gluten-specific T cell responses. Proc Natl Acad Sci USA. 2003;100(21):12390-5.

105. Abraham G, Rohmer A, Tye-Din JA, Inouye $M$. Genomic prediction of celiac disease targeting HLApositive individuals. Genome Med. 2015;7:72.

106. Shan L, Molberg O, Parrot I, et al. Structural basis for gluten intolerance in celiac sprue. Science. 2002;297:2275-9.

107. Arentz-Hansen H, Körner R, Molberg $\varnothing$, et al. The intestinal $\mathrm{T}$ cell response to $\alpha$-gliadin in adult celiac disease is focused on a single deamidated glutamine 
targeted by tissue transglutaminase. J Exp Med. 2000;191(4):603-12.

108. Kagnoff MF, Austin RK, Hubert JJ, Bernardin JE, Kasarda DD. Possible role for a human adenovirus in the pathogenesis of celiac disease. J Exp Med. 1984;160(5):1544-57.

109. De Palma G, Capilla A, Nova E, Castillejo G, Varea V, Pozo T, Garrote JA, Polanco I, López A, RibesKoninckx $\mathrm{C}$, et al. Influence of milk-feeding type and genetic risk of developing coeliac disease on intestinal microbiota of infants: the PROFICEL study. PLoS One. 2012; 7:e30791.

110. Olivares M, Neef A, Castillejo G, Palma GD, Varea V, Capilla A, et al. The HLA-DQ2 genotype selects for early intestinal microbiota composition in infants at high risk of developing coeliac disease. Gut. 2015;64:406-17.

111. Sollid LM, Lie BA. Celiac disease genetics: current concepts and practical applications. Clin Gastroenterol Hepatol. 2005;3:843-51.

112. Alaedini A, Green PH. Narrative review: celiac disease: understanding a complex autoimmune disorder. Ann Intern Med. 2005;142:289-98.

113. Husby S, Koletzko S, Korponay-Szabo IR, et al. European Society for pediatric gastroenterology, hepatology, and nutrition guidelines for the diagnosis of coeliac disease. J Pediatr Gastroenterol Nutr. 2012;54:136-60.

114. Catassi C, Fasano A. Celiac disease diagnosis: simple rules are better than complicated algorithms. Am J Med. 2010;123:691-3.

115. Rubio-Tapia A, Hill ID, Kelly CP, Calderwood AH, Murray JA. ACG clinical guidelines: diagnosis and management of celiac disease. Am J Gastroenterol. 2013;108:656-76.

116. Rostom A, Murray JA, Kagnoff MF. American Gastroenterological Association (AGA) institute technical review on the diagnosis and management of celiac disease. Gastroenterology. 2006;131:1981-2002.

117. Hill ID, Dirks MH, Liptak GS, Colletti RB, Fasano A, Guandalini S, Hoffenberg EJ, Horvath K, Murray JA, Pivor $\mathrm{M}$, et al. Guideline for the diagnosis and treatment of celiac disease in children: recommendations of the North American Society for Pediatric Gastroenterology, Hepatology and Nutrition. J Pediatr Gastroenterol Nutr. 2005;40:1-19.

118. Alamanos Y, Drosos AA. Epidemiology of adult rheumatoid arthritis. Autoimmun Rev. 2005;4:130-6.
119. Stastny P. Mixed lymphocyte cultures in rheumatoid arthritis. Eur J Clin Invest. 1976;57:1148-57.

120. Barton A, Worthington J. Genetic susceptibility to rheumatoid arthritis: an emerging picture. Arthritis Rheum. 2009;61:1441-6.

121. Gregersen PK, Silver J, Winchester RJ. The shared epitope hypothesis. An approach to understanding the molecular genetics of susceptibility to rheumatoid arthritis. Arthritis Rheumatol. 1987;30:1205-13.

122. Silver J, Goyert SM (1985) Epitopes are the functional units of Ia molecules and form the molecular basis for disease susceptibility, human class II histocompatibility antigens. In: Ferrone S, Solheim BG, Moller E, editors. HLA class II antigens: a comprehensive review of structure and function. Berlin, Springer, p 32-48.

123. Stastny P. Association of the B-cell alloantigen DRw4 with rheumatoid arthritis. N Engl J Med. 1978;298:869-71.

124. Gonzalez-Gay MA, Hajeer AH, Dababneh A, et al. Seronegative rheumatoid arthritis in elderly and polymyalgia rheumatica have similar patterns of HLA association. J Rheumatol. 2001;28:122-5.

125. Weyand CM, Klimiuk PA, Goronzy JJ. Heterogeneity of rheumatoid arthritis: from phenotypes to genotypes. Semin Immunopathol. 1998;20(1-2):5-22.

126. MacGregor A, Ollier W, Thomson W, Jawaheer D, Silman A. HLA-DRB1* 0401/0404 genotype and rheumatoid arthritis: increased association in men, young age at onset, and disease severity. J Rheumatol. 1995;22(6):1032-6.

127. Hughes LB, Morrison D, Kelley JM, et al. The HLADRB1 shared epitope is associated with susceptibility to rheumatoid arthritis in African Americans through European genetic admixture. Arthritis Rheumatol. 2008;58:349-58.

128. Lee HS, Lee KW, Song GG, Kim HA, Kim SY, Bae SC. Increased susceptibility to rheumatoid arthritis in Koreans heterozygous for HLA-DRB1*0405 and ${ }^{*} 0901$. Arthritis Rheum. 2004;50:3468-75.

129. van der Woude D, et al. Protection against anticitrullinated protein antibody-positive rheumatoid arthritis is predominantly associated with HLADRB1*1301: a meta-analysis of HLA-DRB1 associations with anti-citrullinated protein antibody-positive and anti-citrullinated protein antibodynegative rheumatoid arthritis in four European populations. Arthritis Rheumatol. 2010;62:1236-45. 
130. Turesson C, Schaid DJ, Weyand CM, Jacobsson LT, Goronzy JJ, Petersson IF, et al. The impact of HLADRB1 genes on extra-articular disease manifestations in rheumatoid arthritis. Arthritis Res Ther. 2005;7(6):R1386-93.

131. Anderson KM, Roark CL, Portas M, Aubrey MT, Rosloniec EF, et al. A molecular analysis of the shared epitope hypothesis: binding of arthritogenic peptides to $\mathrm{DRB} 1{ }^{*} 04$ alleles. Arthritis Rheumatol. 2016;68:1627-36.

132. Roark CL, Anderson KM, Aubrey MT, Rosloniec EF, Freed BM. Arthritogenic peptide binding to DRB1*01 alleles correlates with susceptibility to rheumatoid arthritis. J Autoimmun. 2016;72:25-32.

133. Raychaudhuri $\mathrm{S}$, et al. Five amino acids in three HLA proteins explain most of the association between MHC and seropositive rheumatoid arthritis. Nat Genet. 2012;44:291-6.

134. Viatte S, et al. Association of HLA-DRB1 haplotypes with rheumatoid arthritis severity, mortality, and treatment response. JAMA. 2015;313:1645-56.

135. Ling SF, Viatte S, Lunt M, Van Sijl AM, Silva-Fernandez L, Symmons DP, Young A, et al. HLA-DRB1 amino acid positions $11 / 13,71$, and 74 are associated with inflammation level, disease activity, and the health assessment questionnaire score in patients with inflammatory polyarthritis. Arthritis Rheumatol. 2016;68:2618-28.

136. Huizinga TW, Amos CI, van der Helm-van Mil AH, Chen W, van Gaalen FA, Jawaheer D, Schreuder GM, Wener M, Breedveld FC, Ahmad N, Lum RF, de Vries RR, Gregersen PK, Toes RE, Criswell LA. Refining the complex rheumatoid arthritis phenotype based on specificity of the HLA-DRB1 shared epitope for antibodies to citrullinated proteins. Arthritis Rheumatol. 2005;52(11):3433-8.

137. Klareskog L, Stolt $\mathrm{P}$, Lundberg K, Källberg H, Bengtsson C, Grunewald J, et al. A new model for an etiology of rheumatoid arthritis: smoking may trigger HLA-DR (shared epitope)-restricted immune reactions to autoantigens modified by citrullination. Arthritis Rheumatol. 2006;54:38-46.
138. Kim K, Jiang X, Cui J, et al. Interactions between amino-acid-defined MHC class II variants and smoking for seropositive rheumatoid arthritis. Arthritis Rheumatol. 2015;67(10):2611-23.

139. Jiang X, Kallberg H, Chen Z, et al. An Immunochipbased interaction study of contrasting interaction effects with smoking in ACPA-positive versus ACPAnegative rheumatoid arthritis. Rheumatology (Oxford). 2016;55(1):149-55.

140. Aletaha D, Neogi T, Silman AJ, Funovits J, Felson DT, Bingham CO III, Birnbaum NS, Burmester GR, Bykerk VP, Cohen MD, Combe B, Costenbader KH, Dougados M, Emery P, Ferraccioli G, JMW H, Hobbs K, TWJ H, Kavanaugh A, Kay J, Kvien TK, Laing T, Mease P, Ménard HA, Moreland LW, Naden RL, Pincus T, Smolen JS, Stanislawska-Biernat E, Symmons D, Tak PP, Upchurch KS, Vencovsky J, Wolfe F, Hawker G. 2010 rheumatoid arthritis classification criteria: an American College of Rheumatology/European League Against Rheumatism collaborative initiative. Ann Rheum Dis. 2010;69:1580-8.

141. Berglin E, Padyukov L, Sundin U, et al. A combination of autoantibodies to cyclic citrullinated peptide (CCP) and HLA-DRB1 locus antigens is strongly associated with future onset of rheumatoid arthritis. Arthritis Res Ther. 2004;6(4):R303-8.

142. Van der Cruyssen B, Hoffman IEA, Peene I, et al. Prediction models for rheumatoid arthritis during diagnostic investigation: evaluation of combinations of rheumatoid factor, anti-citrullinated protein/peptide antibodies and the human leucocyte antigen-shared epitope. Ann Rheum Dis. 2007;66(3):364-9.

143. O'Dell JR, Nepom BS, Haire C, et al. HLA-DRB1 typing in rheumatoid arthritis: predicting response to specific treatments. Ann Rheum Dis. 1998;57(4):209-13.

144. Danila MI, Hughes LB, Bridges SL. Pharmacogenetics of etanercept in rheumatoid arthritis. Pharmacogenomics. 2008;9:1011-5. 